\title{
HSP90 inhibitors induce desensitization of EGF receptor via p38 MAPK-mediated phosphorylation at Ser1046/1047 in human pancreatic cancer cells
}

\author{
SEIJI ADACHI ${ }^{1,2}$, ICHIRO YASUDA ${ }^{1}$, MASANORI NAKASHIMA $^{1}$, TAKAHIRO YAMAUCHI ${ }^{1}$, \\ JUNICHI YAMAUCHI $^{2}$, HIDEO NATSUME ${ }^{2}$, HISATAKA MORIWAKI ${ }^{1}$ and OSAMU KOZAWA ${ }^{2}$
}

Departments of ${ }^{1}$ Gastroenterology and ${ }^{2}$ Pharmacology, Gifu University Graduate School of Medicine, Gifu 501-1194, Japan

Received December 21, 2009; Accepted February 9, 2010

DOI: 10.3892/or_00000815

\begin{abstract}
Heat shock protein (HSP) 90 is known to be a molecular chaperone whose association is required for the stability and function of oncogenic protein including epidermal growth factor receptor (EGFR) that promotes cancer cell growth. Therefore, HSP90 is a promising target for therapy against cancer including in the pancreas, some of which are highly dependent on EGFR. We investigated the effects of HSP90 inhibitors on cytotoxicity and desensitization of EGFR in human pancreatic cancer cells (KP3, $\mathrm{BxPc} 3$ and AsPc1). 17-allylamino-17-demethoxy-geldanamycin (17-AAG), an inhibitor of HSP90, caused desensitization of EGFR in a time-dependent manner, concurrently inducing phosphorylation of EGFR at Ser1046/ 1047 (Ser1046/7), a site which plays an important role in EGFR desensitization in these pancreatic cancer cells. We also found similar effects in KP3 cells treated with other HSP90 inhibitors, geldanamycin and 17-dimethylaminoethylamino-17-demethoxy-geldanamycin (17-DMAG). In KP3 cells, 17-AAG induced activation of either p44/p42 mitogenactivated protein kinase (MAPK) or p38 MAPK. Interestingly, whereas the inhibition of $\mathrm{p} 44 / \mathrm{p} 42$ MAPK attenuated neither phosphorylation of EGFR at Ser1046/7 nor desensitization of EGFR, the phosphorylation at Ser1046/7 induced by 17-AAG was markedly attenuated by the inhibition of p38 MAPK, indicating that p38 MAPK induced this phosphorylation. Moreover, the inhibition of p38 MAPK significantly attenuated 17-AAG-induced EGFR desensitization. These results strongly suggest that EGFR phosphorylation at Ser1046/7 via activation of p38 MAPK induced by HSP90 inhibitors plays a pivotal role in EGFR desensitization in human pancreatic cancer cells.
\end{abstract}

Correspondence to: Dr Seiji Adachi, Department of Gastroenterology, Gifu University Graduate School of Medicine, Gifu 501-1194, Japan

E-mail: seijiadachi0123@gmail.com

Key words: HSP90, EGFR, desensitization, p38 MAPK, pancreatic cancer

\section{Introduction}

Pancreatic cancer is a highly lethal disease that is usually diagnosed at a late stage and is not amenable to surgery. The overall 5-year survival rate for pancreatic cancer patients is only $4 \%$ due to the lack of treatment options (1). Gemcitabine is currently considered to be the standard of care for the treatment of advanced pancreatic cancer. Moreover, in clinical trials, combination of gemcitabine with certain other cytotoxic drugs, including cisplatin, oxaliplatin, capecitabine, and 5-fluorouracil have been undertaken, but all have failed to provide substantial increases in survival benefit (2).

The receptor tyrosine kinase (RTK) family of cell surface receptors includes the epidermal growth factor receptor (EGFR) and its relatives ErbB2/HER2, ErbB3/HER3 and ErbB4/HER4. In general, binding of ligand to EGFR leads to receptor dimerization, autophosphorylation and activation of several downstream signaling pathways, which upon activation lead to cell proliferation, motility and enhanced survival (3). Expression of EGFR is known to be overexpressed in pancreatic adenocarcinoma (4). EGFR activation reportedly has the ability to transform normal cells to a neoplastic phenotype when it is expressed at a high level or when an activated mutation is introduced into it $(5,6)$. Therefore, activation of EGFR appears to have an important role in the growth and progression of many types of cancers including pancreas and the EGFR-mediated pathway is one of the most promising targets for the development of new strategies in anti-cancer treatments. Agents capable of inhibiting EGFR activity which results in the suppression of cell proliferation and angiogenesis have significant potential for use in chemotherapy for the treatment of multiple malignancies (4). Increasing evidence shows the efficacy of EGFR-targeted agents, including monoclonal antibodies on the one hand, which are registered for metastatic colorectal cancer (7), and tyrosine kinase inhibitors on the other, which have been available for advanced lung cancer (8).

It is generally recognized that heat shock proteins (HSPs) function as molecular chaperones in protein folding, oligomerization and translocation and are often found to be overexpressed in many types of cancers. Among them, HSP90 is an abundant molecular chaperone and represents $1-2 \%$ of 
total cellular protein, which increases to $4-6 \%$ under stress (9). HSP90 is a molecular chaperone whose association is required for the stability and function of multiple mutated, chimeric and overexpressed signaling proteins that promote the growth and/or survival of cancer cells. The N-terminal domain contains a unique nucleotide binding pocket that binds both ATP and ADP. Conformational changes that occur upon binding and hydrolysis of ATP regulate the ability of the chaperone to bind its client proteins (10). HSP90 client proteins include, HER-2 (11), p53, MAPK/Erk, Akt (12), the transcription factor HIF-1 $\alpha$ (13), and mutated EGFR (14). Chaperone activity is also regulated by the binding of cochaperone proteins including Hsp70, Hip, Hop, CDC37/p50, immunophilins and Aha1 $(10,15)$.

HSP90 inhibitors, by interfering ATP binding, cause the destabilization and eventual degradation of HSP90 client proteins. Among HSP90 inhibitors, 17-allylamino-17-demethoxygeldanamycin (17-AAG), is currently in completing phase I/II clinical trials as a single agent cancer therapeutic (16). As for EGFR, it has been shown that L858R and deletion mutant EGFR proteins found in non-small cell lung cancer cells interact with the chaperone and are more sensitive to degradation following HSP90 inhibition than wild-type EGFR (14).

Receptor desensitization is the most prominent regulatory system of EGFR signal attenuation and involves the internalization and subsequent degradation of the activated receptor in the lysosomes (17). With the current knowledge of the mechanism underlying EGFR desensitization, this molecular event seems to involve several important phosphorylation sites. One is the phosphorylation at Tyr1045, which provides a docking site for the ubiquitin ligase $\mathrm{c}-\mathrm{Cbl}$ resulting in ubiquitination of the EGFR (18) and the others are the phosphorylation at serine or threonine residues, which are thought to represent a mechanism for attenuation of the receptor kinase activity $(19,20)$. Among the major sites of serine and threonine phosphorylation of the EGFR, it has previously been shown that the serine 1046/1047 (Ser1046/7) phosphorylation sites are required for EGFR desensitization in EGF-treated cells (21). Moreover, mutations of Ser1046/7 are reported to cause a marked inhibition of the EGFstimulated endocytosis and desensitization of cell surface receptors (20). In addition, we have recently reported that p38 mitogen-activated protein kinase (MAPK) controls EGFR desensitization via phosphorylation at Ser1046/7 (22), suggesting that serine phosphorylation of EGFR or p38 MAPK activation might be considered a new therapeutic target especially to counter cancer cells of the colon, lung, pancreas and breast that highly express EGFR.

In this study, we investigated the anti-cancer effects of HSP90 inhibitors, focusing on the EGFR desensitization and its mechanism in human pancreatic cancer cells. HSP90 inhibitors caused desensitization of EGFR mediated by its phosphorylation at Ser1046/7 via activation of p38 MAPK in these cells.

\section{Materials and methods}

Cell culture and chemicals. Human pancreatic cancer cells were grown in Roswell Park Memorial Institute (RPMI)-1640
(Invitrogen, San Diego, CA), containing 10\% fetal calf serum (FCS) as described previously (23). Geldanamycin was purchased from Invivogen, Sigma Chemicals Co. (St. Louis, MO). SB203580, PD98059, 17-AAG and 17-dimethylaminoethyl-amino-17-demethoxygeldanamycin (17-DMAG) were purchased from Calbiochem-Novabiochem Corporation (La Jolla, CA), respectively. They were solubilized in DMSO. BIRB0796 was obtained from Dr Philip Cohen (University of Dundee, UK).

Cell viability assays. Cell viability assay was performed using the 3-(4,5-dimethylthiazol-2-yl)-2,5-diphenyltetrazolium bromide (MTT) cell proliferation kit I (Roche Diagnostics Co., Indianapolis, IN), according to the instructions of the manufacturer. In brief, pancreatic cancer cell lines were plated onto 96 -well plates $\left(3 \times 10^{3}\right.$ cells/well) and $24 \mathrm{~h}$ later, the cells were treated with the indicated doses $(0-1000 \mathrm{nM})$ of the indicated compounds for $72 \mathrm{~h}$ in RPMI-medium containing $10 \%$ FCS. The medium and drugs were not changed during this time period. All assays were done in triplicate.

Western blot analysis. The cells were lysed in lysis buffer [20 mM Tris (pH 7.5), $150 \mathrm{mM} \mathrm{NaCl}, 1 \mathrm{mM}$ EDTA, $1 \mathrm{mM}$ EGTA, 1\% Triton X-100, $2.5 \mathrm{mM}$ sodium pyrophosphate, $50 \mathrm{mM} \mathrm{NaF}, 50 \mathrm{mM}$ HEPES, $1 \mathrm{mM} \mathrm{Na} \mathrm{VO}_{4}$ and $2 \mathrm{mM}$ phenylmethylsulfonyl fluoride (PMSF)] and scraped from the Petri dishes. Protein extracts were then examined by Western blot analysis as previously described (24). The antibodies used in these studies were anti-EGFR, anti-GAPDH (Santa Cruz Biotechnology, Santa Cruz, CA), anti-phospho-EGFR (Ser1046/7), anti-p44/p42 MAPK, anti-phospho-p44/p42 MAPK, anti-phospho-p38 MAPK, anti-p38 MAPK, antiphospho-stress-activated protein kinase/c-Jun-N-terminal kinase (SAPK/JNK) and anti-SAPK/JNK (Cell Signaling, Beverly, MA). Anti-mouse IgG or anti-rabbit IgG antibodies (Amersham Pharmacia Biotech, Buckinghamshire, UK) were used as the secondary antibodies. Each membrane was developed using an enhanced chemiluminescence detection system (Amersham Pharmacia Biotech).

Statistical analysis. Quantitative analysis of the indicated protein band was calculated as follows; the background was first subtracted from the signal intensity (total optical density) of each protein signal and then each value was normalized with GAPDH or total protein and expressed as relative signal intensity with respect to the respective control. The data are presented as the mean \pm SEM of triplicate determinations, and analyzed by ANOVA followed by the Bonferroni method for multiple comparisons between pairs. A p $<0.05$ was considered statistically significant.

\section{Results}

HSP90 inhibitors exert anti-proliferative effects in human pancreatic cancer cells. It has previously been reported that overexpression of EGFR in pancreatic cancers has an important role in its aberrant growth and progression (4). We first performed cell proliferating assay using MTT to examine the anti-cancer effects of 17-AAG, an HSP90 inhibitor, in $\mathrm{BxPc} 3, \mathrm{AsPc} 1$ and $\mathrm{KP} 3$ pancreatic cells. As 
A

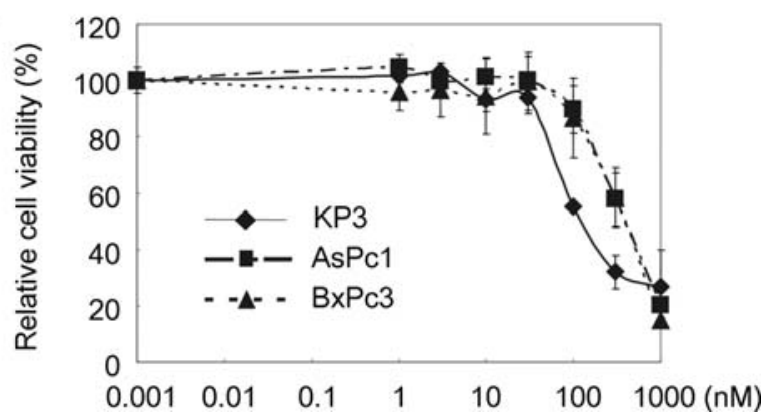

B

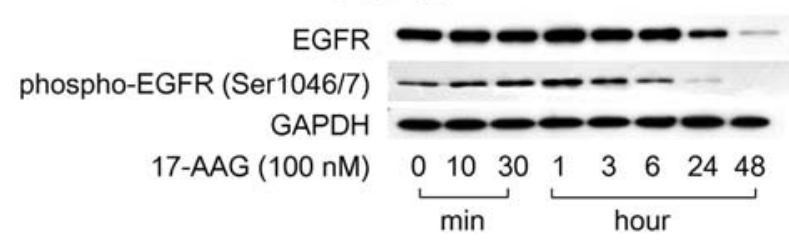

C

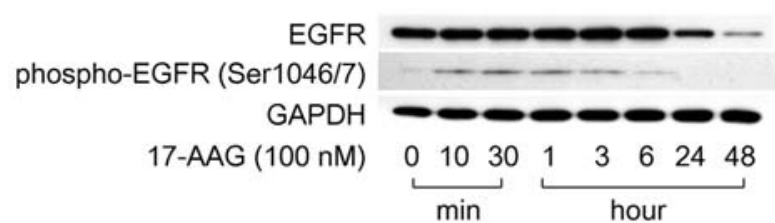

D

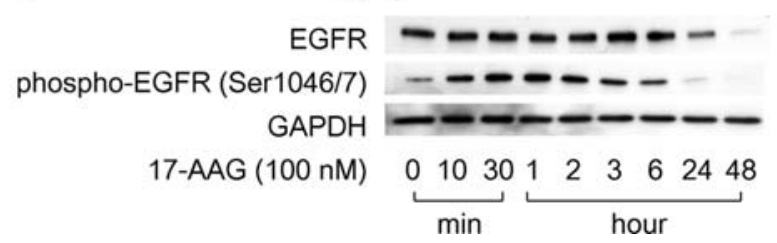

Figure 1. (A) Inhibition of cell growth by 17-AAG in pancreatic cancer cells. Cell viability assay was performed using the MTT cell proliferation kit I. Results are expressed as percentage of growth with $100 \%$ representing control cells treated with vehicle alone. Bars designate SD of triplicate assays. (B-C) 17-AAG caused desensitization of EGFR and phosphorylation of EGFR at Ser1046/7 in KP3 (A), BxPc3 (B) and AsPc1 (C) pancreatic cancer cells. The indicated cells were treated with 17-AAG at a dose of $100 \mathrm{nM}$, respectively, for the indicated periods and protein extracts were then harvested and examined by Western blotting using anti-EGFR, antiphospho-EGFR at Ser1046/7 and anti-GAPDH antibodies.

shown in Fig. 1A, the $\mathrm{IC}_{50}$ values of $17-\mathrm{AAG}$ in $\mathrm{KP} 3$ cells was $70 \mathrm{nM}$, whereas those in BxPc3 and AsPc1 were 300 and $400 \mathrm{nM}$, respectively. These results suggest that 17-AAG has potent anti-cancer effect in pancreatic cancer cells.

17-AAG caused desensitization of EGFR, concurrently inducing phosphorylation of EGFR at Ser1046/7 in pancreatic cancer cells. We next examined the effect of 17-AAG on the desensitization of EGFR in these pancreatic cancer cells. As shown in Fig. 1B-D, when the cells were treated with 17-AAG, the protein level of EGFR was time-dependently decreased, respectively (Fig. 1B-D, upper panels). In addition, we examined the effects of 17-AAG on the phosphorylation of EGFR at Ser1046/7, since this phosphorylation has been reported to play an important role in EGFR desensitization $(20,25)$. Interestingly, 17-AAG induced phosphorylation of
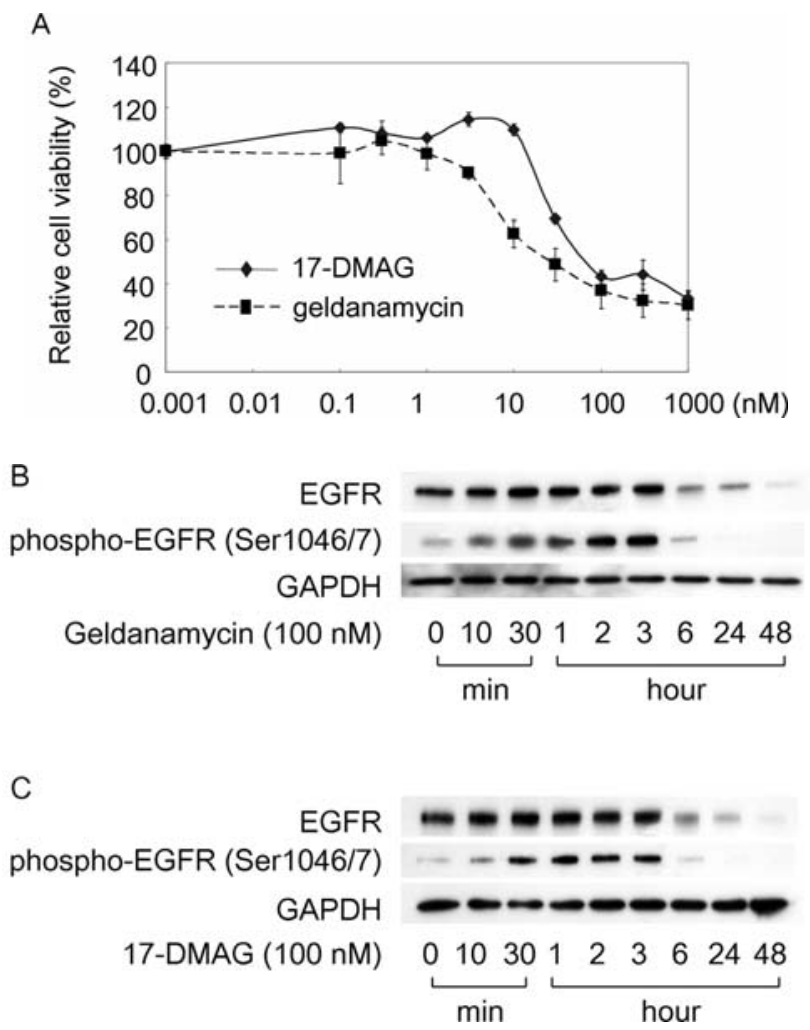

Figure 2. (A) Geldanamycin and 17-DMAG caused inhibition of cell growth in KP3 pancreatic cancer cells. Cell viability assay was performed using the MTT cell proliferation kit I. Results are expressed as percentage of growth with $100 \%$ representing control cells treated with vehicle alone. Bars designate SD of triplicate assays. (B) Geldanamycin and 17-DMAG caused desensitization of EGFR and phosphorylation of EGFR at Ser1046/7 in KP3 pancreatic cancer cells KP3 cells were treated with the indicated compounds at a dose of $100 \mathrm{nM}$, respectively, for the indicated periods and protein extracts were then harvested and examined by Western blotting using antiEGFR, anti-phospho-EGFR at Ser1046/7 and anti-GAPDH antibodies.

EGFR at Ser1046/7 at a peak of $30 \mathrm{~min}$ to $1 \mathrm{~h}$ (Fig. 1B-D, middle panel, respectively). Significant effect by $17-\mathrm{AAG}$ on this phosphorylation was observed within $10 \mathrm{~min}$ in these types of pancreatic cancer cells. Since EGFR proteins were concurrently decreased, it seems that phosphorylation of EGFR at Ser1046/7 induced by 17-AAG correlates with its desensitization in these pancreatic cells.

Other HSP90 inhibitors also caused EGFR desensitization concurrently inducing phosphorylation of EGFR at Ser1046/7. To prove that these results (Fig. 1) are not confined to 17-AAG, we examined the effects of geldanamycin and 17-DMAG as other HSP90 inhibitors on cytotoxicity and desensitization of EGFR. We performed a cell proliferating assay using MTT in KP3 pancreatic cells and found that geldanamycin as well as 17-DMAG exerted similar effects on cytotoxicity $\left(\mathrm{IC}_{50} ; 30\right.$ and $100 \mathrm{nM}$, respectively) in KP3 cells (Fig. 2A). In addition, treatment of the cells with either $100 \mathrm{nM}$ of geldanamycin or 17-DMAG for $6 \mathrm{~h}$ resulted in significant decrease in EGFR protein level (Fig. 2B and C, upper panel, respectively). Moreover, treatment of the cells with geldanamycin or 17-DMAG induced phosphorylation of EGFR at Ser1046/7 at a peak of $30 \mathrm{~min}$ to $3 \mathrm{~h}$ (Fig. 2B and C, middle panel, respectively). Therefore, 


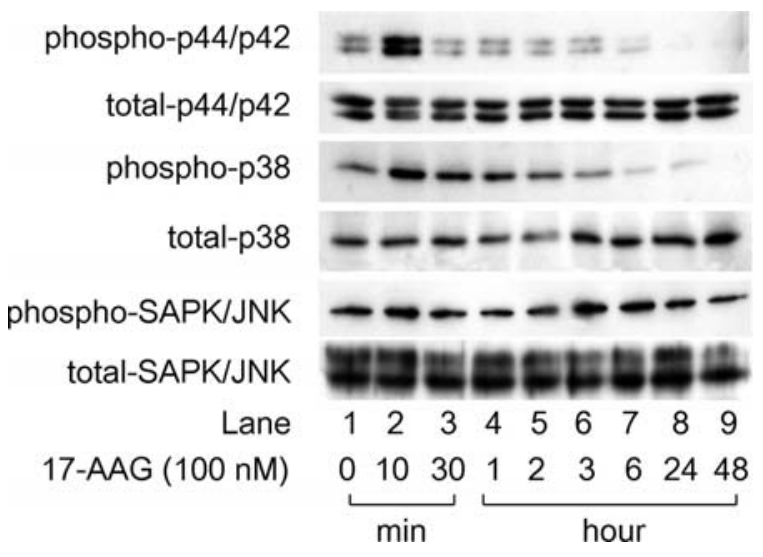

Figure 3. 17-AAG induced phosphorylation of both p44/p42 MAPK and p38 MAPK, but not SAPK/JNK in KP3 pancreatic cancer cells. KP3 cells were treated with 17-AAG $(100 \mathrm{nM})$ for the indicated periods and protein extracts were then harvested and examined by Western blotting using anti-phosphop44/p42 MAPK, anti-p44/p42 MAPK, anti-phospho-p38 MAPK, anti-p38 MAPK, anti-phospho-SAPK/JNK and anti-SAPK/JNK antibodies. it is likely that the suppression of pancreatic cancer cell proliferation caused by inhibition of HSP90 is generally correlated with either phosphorylation of EGFR at Ser1046/7 or its desensitization.

HSP90 inhibitors induced activation of p44/p42 MAPK and p38 MAPK in KP3 human pancreatic cancer cells. It has been shown that the inhibition of HSP90 destabilizes a large number of oncogenes that are themselves overexpressed, mutated or otherwise activated during malignant progression (26). HSP90 client proteins include various molecules associated with the initiation and development of cancer, such as the kinases c-Raf1, HER-2, Akt, cdk4 and p53. In the present study, we examined the effect of 17-AAG on activation of kinase cascades, especially the MAP kinase superfamily. We found that 17-AAG induced activation of both p44/p42 MAPK and p38 MAPK in KP3 cells (Fig. 3). On the contrary, 17-AAG had little effect on the activation of SAPK/JNK (Fig. 3). These results led us to further investigate
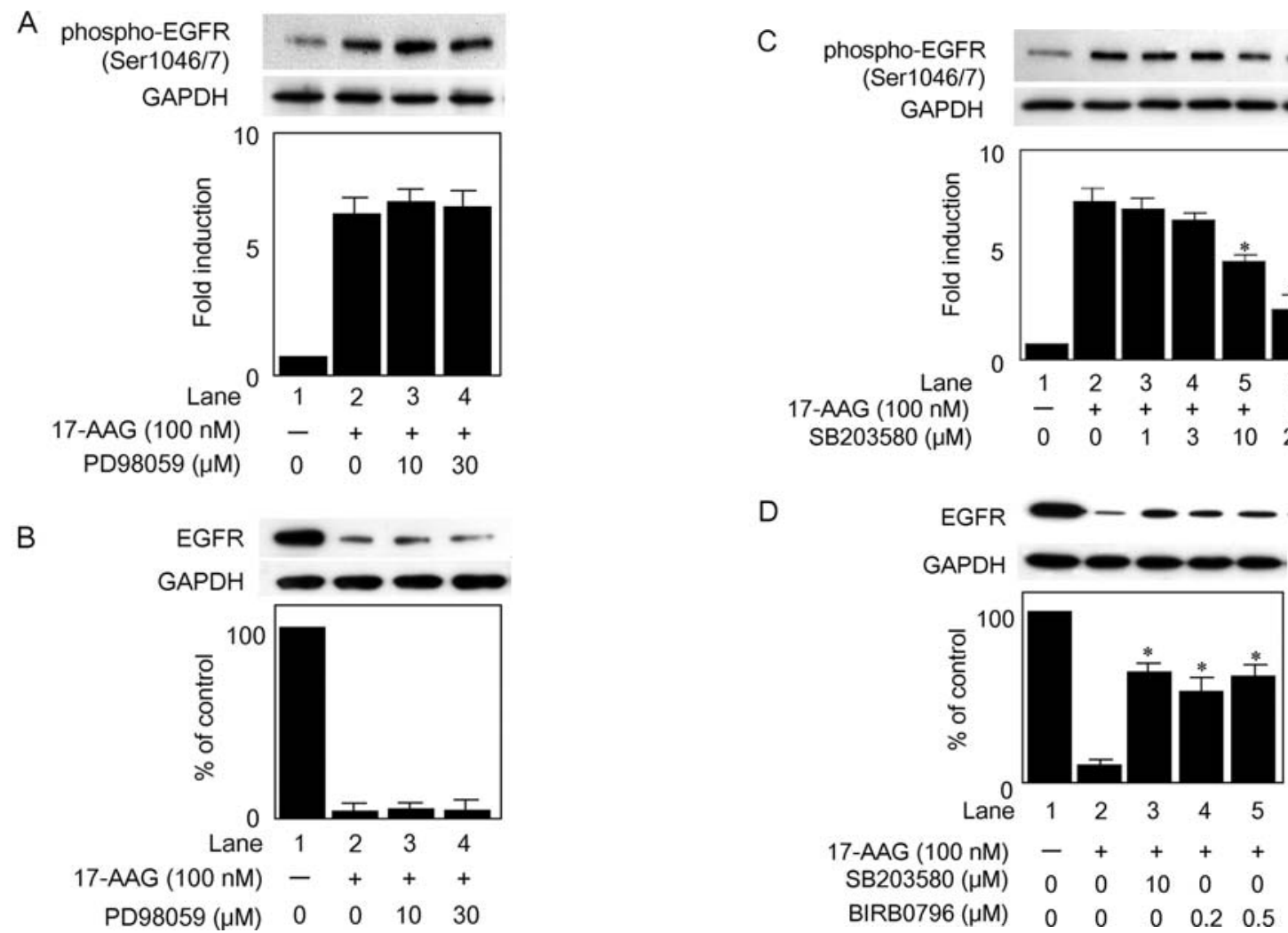

Figure 4. The inhibition of p38 MAPK, but not p44/p42 MAPK suppressed the phosphorylation of EGFR at Ser1046/7 and desensitization of EGFR induced by 17-AAG in KP3 pancreatic cancer cells. (A) KP3 cells were pretreated with PD98059 at the indicated doses for $1 \mathrm{~h}$, followed by treatment with 17-AAG $(100 \mathrm{nM})$ for $1 \mathrm{~h}$. Protein extracts were then harvested and examined by Western blotting using anti-phospho-EGFR at Ser1046/7 and anti-GAPDH antibodies. The lower bar graph shows quantification data for the relative levels of phospho-EGFR at Ser1046/7, after normalization with respect to GAPDH, as determined by densitometry. (B) KP3 cells were pretreated with PD98059 at the indicated doses for $1 \mathrm{~h}$, followed by treatment with 17 -AAG (100 nM) for $48 \mathrm{~h}$. Protein extracts were then harvested and examined by Western blotting using anti-EGFR and anti-GAPDH antibodies. The lower bar graph shows quantification data for the relative levels of EGFR, after normalization with respect to GAPDH, as determined by densitometry. (C) KP3 cells were pretreated with SB203580 at the indicated doses for $1 \mathrm{~h}$, followed by treatment with 17-AAG (100 nM) for $1 \mathrm{~h}$. Protein extracts were then harvested and examined by Western blotting using anti-phospho-EGFR at Ser1046/7 and anti-GAPDH antibodies. The lower bar graph shows quantification data for the relative levels of phospho-EGFR at Ser1046/7, after normalization with respect to GAPDH, as determined by densitometry. (D) KP3 cells were pretreated with either SB203580 or BIRB0796, p38 MAPK inhibitors, at the indicated doses for $1 \mathrm{~h}$, followed by treatment with 17 -AAG (100 nM) for $48 \mathrm{~h}$. Protein extracts were then harvested and examined by Western blotting using anti-EGFR and anti-GAPDH antibodies. The lower bar graph shows quantification data for the relative levels of EGFR, after normalization with respect to GAPDH, as determined by densitometry. The asterisks indicate significant increase $\left({ }^{*}\right.$ p $\left.<0.05\right)$ as compared to the control (lane 2), respectively. 
whether activation of either p44/p42 MAPK or p38 MAPK plays a role in the desensitization of EGFR induced by HSP90 inhibitors in pancreatic cancer cells.

Inhibition of p38 MAPK, but not p44/p42 MAPK suppressed the phosphorylation of EGFR at Ser1046/7. As shown in Fig. 3, 17-AAG induced the activation of p44/p42 MAPK and p38 MAPK in KP3 cells. In addition, HSP90 inhibitors including 17-AAG caused the phosphorylation of EGFR at Ser1046/7 (Figs. 1 and 2). Therefore, it is of interest to examine the effects of MEK1/2 specific inhibitor, PD98059 (27) or p38 MAPK specific inhibitor, SB203580 (28) on the phosphorylation of EGFR at Ser1046/7 and the desensitization of EGFR induced by 17-AAG. As shown in Fig. 4A, the phosphorylation of EGFR at Ser1046/7 induced by 17-AAG was not suppressed even when the cells were pretreated with up to $30 \mu \mathrm{M}$ of PD98059 (Fig. 4A), a dose of which strongly suppressed the phosphorylation of p44/p42 MAPK induced by 17-AAG (data not shown). Additionally, PD98059 failed to reverse the desensitization of EGFR induced by $17-A A G$ (Fig. 4B). Therefore, it is unlikely that p44/p42 MAPK is involved in the desensitization of EGFR by HSP90 inhibitors. On the contrary, 17-AAG-induced phosphorylation of EGFR at Ser1046/7 was significantly inhibited by treatment with SB203580 at doses of over $10 \mu \mathrm{M}$ (Fig. 4C). Moreover, EGFR desensitization induced by 17-AAG was significantly restored when the cells were pretreated with specific inhibitors of p38 MAPK, either SB203580 or BIRB0796 (29) (Fig. 4D). These results strongly suggest that phosphorylation of EGFR at Ser1046/7 was mediated through the p38 MAPK pathway and that the p38 MAPK pathway, at least in part, acts in 17-AAG-induced EGFR desensitization in KP3 pancreatic cancer cells.

\section{Discussion}

The benzoquinone ansamycin antibiotic geldanamycin was discovered as a natural product which disrupts HSP90 chaperone activities and its less toxic derivative 17-AAG has been shown to possess strong anti-proliferative and apoptotic activity in cancer cells, whereas 17-AAG has demonstrated potent anti-tumor activity in several human xenograft models, including breast, prostate and colon cancer (30). Therefore, we examined the effect of 17-AAG on anti-proliferative effect, especially focusing on desensitization of EGFR in various kinds of pancreatic cancer cells. Our findings show in pancreatic cancer cells that: i) EGFR is targeted by HSP90 inhibitors; ii) HSP90 inhibitors induce activation of p38 MAPK; iii) the inhibition of HSP90 induces the EGFR phosphorylation at Ser1046/7, a site which is reported to play an important role in its desensitization; and iv) p38 MAPK regulates desensitization of EGFR via its phosphorylation at Ser1046/7. Our present study in pancreatic cancer cells is consistent with our previous report showing that p38 MAPK directs EGFR toward desensitization via its phosphorylation at Ser1046/7 (22), because in the present study we found that HSP90 inhibitors induced p38 MAPK, leading to EGFR phosphorylation at Ser1046/7.

Recent study shows that several HSP90 client proteins have been validated as clinically important therapeutic targets for treatment of cancer, and HSP90 inhibitors are recognized as potentially beneficial anti-cancer agents (31). More than 200 signaling proteins have been found to be regulated by HSP90. For example, BCR-ABL is degraded after HSP90 inhibition and imatinib-resistant BCR-ABL point mutants remain sensitive to HSP90 inhibitors (32). Lung cancers are sometimes driven by mutant HER-2, mutant B-Raf, or mutant or overexpressed c-Met, all of which are also degraded by HSP90 inhibition (33). Moreover, it has been reported that HSP90 plays a unique anti-apoptotic role in small cell lung cancer cells, so that HSP90 inhibition results in substantial cell death in both chemosensitive and chemoresistant cell lines (33). Since many of HSP90-regulated signaling proteins are involved in cancer cell growth, HSP90 inhibitors are recognized as a promising new class of anti-cancer drugs (34). Moreover, HSP90 in human pancreatic cancer is reportedly expressed 6- to 7-fold higher than normal tissues (35). In addition, enhanced EGFR signaling pathway contributes to pancreatic cancer (4). We herein showed that HSP90 inhibitors induced EGFR desensitization in pancreatic cancer cells (Figs. 1 and 2), thus indicating that HSP90 inhibitors might be useful for control of pancreatic cancer.

There is accumulating evidence that activation of p38 MAPK has a suppressive effect on tumorigenesis (36) and that a variety of agents, in addition to specific ligands such as EGF and transforming growth factor $\alpha$, can induce activation of p38 MAPK and internalization of EGFR into endosomal vesicles. These agents include oxidative stress (37), ultraviolet irradiation (38), gemcitabine (39) and cisplatin (40). We have previously reported that (-)-epigallocatechin gallate (EGCG) caused internalization of EGFR into endosomal vesicles (23). Moreover, we have recently shown that EGCG downregulates EGFR via phosphorylation at Ser1046/7 by p38 MAPK in colon cancer cells (25). In the present study, we investigated the involvement of p38 MAPK in EGFR desensitization induced by HSP90 inhibitors and showed that p38 MAPK activated by HSP90 inhibitors induced desensitization of EGFR via its phosphorylation at Ser1046/7. Based on these findings, it is most likely that p38 MAPK plays a key role in EGFR desensitization.

It has previously been reported that whereas the kinase domain of HER-2 is assembled into a stable complex with HSP90, little or no HSP90 is recovered with EGFR (41). In addition, mutant EGFR is reported to be one of HSP90 clients (14). However, as far as we know, there is no report showing that pancreatic cancer has mutant EGFR. Therefore, our present study provides the first evidence showing that HSP90 inhibitors induced desensitization of wild-type EGFR in pancreatic cancer cells. Our findings may suggest new therapeutic strategies for inhibiting the proliferation of pancreatic cancer that are highly dependent on the function of the EGFR. As mentioned above, gemcitabine is currently considered to be the standard of care for the treatment of advanced pancreatic cancer. Since the potency of combination of gemcitabine with certain other cytotoxic drugs have been investigated in several clinical trials (2), it is of interest to elucidate new combination of gemcitabine and HSP90 inhibitors in human pancreatic cancer. Although our present study elucidated the mechanism underlying EGFR desensitization induced by HSP90 inhibitors, further 
investigation is required to clarify how HSP90 inhibitors activate p38 MAPK and how phosphorylation of EGFR at Ser1046/7 induces desensitization of EGFR.

In conclusion, our results strongly suggest that HSP90 inhibitors cause EGFR desensitization in human pancreatic cancer cells and that activation of p38 MAPK induced by HSP90 inhibitors regulates the desensitization of EGFR via its phosphorylation at Ser1046/7.

\section{Acknowledgements}

We are very grateful to Ms. Yoko Kawamura for her skillful technical assistance. This study was supported in part by Grant-in-Aid for Scientific Research (20790490 to S.A) from the Ministry of Education, Science, Sports and Culture of Japan.

\section{References}

1. Jemal A, Siegel R, Ward E, Murray T, Xu J and Thun MJ: Cancer statistics, 2007. CA Cancer J Clin 57: 43-66, 2007.

2. Sanchez SE and Trevino JG: Current adjuvant and targeted therapies for pancreatic adenocarcinoma. Curr Med Chem 15: 1674-1683, 2008

3. Zandi R, Larsen AB, Andersen P, Stockhausen MT and Poulsen HS: Mechanisms for oncogenic activation of the epidermal growth factor receptor. Cell Signal 19: 2013-2023, 2007.

4. Papageorgio C and Perry MC: Epidermal growth factor receptor-targeted therapy for pancreatic cancer. Cancer Invest 25: 647-657, 2007

5. Velu TJ, Beguinot L, Vass WC, et al: Epidermal-growth-factordependent transformation by a human EGF receptor protooncogene. Science 238: 1408-1410, 1987.

6. Xiong HQ and Abbruzzese JL: Epidermal growth factor receptor-targeted therapy for pancreatic cancer. Semin Oncol 29: 31-37, 2002

7. Baselga J: The EGFR as a target for anticancer therapy - focus on cetuximab. Eur J Cancer 37 (Suppl. 4): S16-S22, 2001.

8. Milano G, Spano JP and Leyland-Jones B: EGFR-targeting drugs in combination with cytotoxic agents: from bench to bedside, a contrasted reality. Br J Cancer 99: 1-5, 2008.

9. Chiosis G: Targeting chaperones in transformed systems, a focus on Hsp90 and cancer. Expert Opin Ther Targets 10: 37-50, 2006.

10. Prodromou C and Pearl LH: Structure and functional relationships of Hsp90. Curr Cancer Drug Targets 3: 301-323, 2003.

11. Smith V, Hobbs S, Court W, Eccles S, Workman P and Kelland LR: ErbB2 overexpression in an ovarian cancer cell line confers sensitivity to the HSP90 inhibitor geldanamycin. Anticancer Res 22: 1993-1999, 2002.

12. Zhang H and Burrows F: Targeting multiple signal transduction pathways through inhibition of Hsp90. J Mol Med 82: 488-499, 2004.

13. Mabjeesh NJ, Post DE, Willard MT, et al: Geldanamycin induces degradation of hypoxia-inducible factor 1alpha protein via the proteosome pathway in prostate cancer cells. Cancer Res 62: 2478-2482, 2002.

14. Shimamura T, Lowell AM, Engelman JA and Shapiro GI: Epidermal growth factor receptors harboring kinase domain mutations associate with the heat shock protein 90 chaperone and are destabilized following exposure to geldanamycins. Cancer Res 65: 6401-6408, 2005.

15. Panaretou B, Siligardi G, Meyer P, et al: Activation of the ATPase activity of hsp90 by the stress-regulated cochaperone aha1. Mol Cell 10: 1307-1318, 2002.

16. Banerji U, Walton M, Raynaud F, et al: Pharmacokineticpharmacodynamic relationships for the heat shock protein 90 molecular chaperone inhibitor 17-allylamino, 17-demethoxygeldanamycin in human ovarian cancer xenograft models. Clin Cancer Res 11: 7023-7032, 2005.

17. Arteaga CL: Epidermal growth factor receptor dependence in human tumors: more than just expression? Oncologist 7 (Suppl. 4): 31-39, 2002.
18. Massie C and Mills IG: The developing role of receptors and adaptors. Nat Rev Cancer 6: 403-409, 2006.

19. Countaway JL, McQuilkin P, Girones N and Davis RJ: Multisite phosphorylation of the epidermal growth factor receptor. Use of site-directed mutagenesis to examine the role of serine/threonine phosphorylation. J Biol Chem 265: 3407-3416, 1990.

20. Countaway JL, Nairn AC and Davis RJ: Mechanism of desensitization of the epidermal growth factor receptor proteintyrosine kinase. J Biol Chem 267: 1129-1140, 1992

21. Theroux SJ, Stanley K, Campbell DA and Davis RJ: Mutational removal of the major site of serine phosphorylation of the epidermal growth factor receptor causes potentiation of signal transduction: role of receptor down-regulation. Mol Endocrinol 6: 1849-1857, 1992.

22. Adachi S, Natsume H, Yamauchi J, et al: p38 MAP kinase controls EGF receptor downregulation via phosphorylation at Ser1046/1047. Cancer Lett 277: 108-113, 2009.

23. Adachi S, Nagao T, To S, et al: (-)-Epigallocatechin gallate causes internalization of the epidermal growth factor receptor in human colon cancer cells. Carcinogenesis 29: 1986-1993, 2008.

24. Adachi S, Nagao T, Ingolfsson HI, et al: The inhibitory effect of (-)-epigallocatechin gallate on activation of the epidermal growth factor receptor is associated with altered lipid order in HT29 colon cancer cells. Cancer Res 67: 6493-6501, 2007.

25. Adachi S, Shimizu M, Shirakami Y, et al: (-)-Epigallocatechin gallate downregulates EGF receptor via phosphorylation at Ser1046/1047 by p38 MAP kinase in colon cancer cells. Carcinogenesis 30: 1544-1552, 2009.

26. Workman P: Overview: translating Hsp90 biology into Hsp90 drugs. Curr Cancer Drug Targets 3: 297-300, 2003.

27. Alessi DR, Cuenda A, Cohen P, Dudley DT and Saltiel AR: PD 098059 is a specific inhibitor of the activation of mitogenactivated protein kinase kinase in vitro and in vivo. J Biol Chem 270: 27489-27494, 1995.

28. Cuenda A, Rouse J, Doza YN, et al: SB 203580 is a specific inhibitor of a MAP kinase homologue which is stimulated by cellular stresses and interleukin-1. FEBS Lett 364: 229-233, 1995.

29. Bain J, Plater L, Elliott M, et al: The selectivity of protein kinase inhibitors: a further update. Biochem J 408: 297-315, 2005.

30. Stravopodis DJ, Margaritis LH and Voutsinas GE: Drugmediated targeted disruption of multiple protein activities through functional inhibition of the Hsp90 chaperone complex. Curr Med Chem 14: 3122-3138, 2007.

31. Soo ET, Yip GW, Lwin ZM, Kumar SD and Bay BH: Heat shock proteins as novel therapeutic targets in cancer. In Vivo 22: 311-315, 2008.

32. Gorre ME, Ellwood-Yen K, Chiosis G, Rosen N and Sawyers CL: BCR-ABL point mutants isolated from patients with imatinib mesylate-resistant chronic myeloid leukemia remain sensitive to inhibitors of the BCR-ABL chaperone heat shock protein 90 . Blood 100: 3041-3044, 2002.

33. Shimamura T and Shapiro GI: Heat shock protein 90 inhibition in lung cancer. J Thorac Oncol 3: S152-S159, 2008.

34. Sharp S and Workman P: Inhibitors of the HSP90 molecular chaperone: current status. Adv Cancer Res 95: 323-348, 2006.

35. Ogata M, Naito Z, Tanaka S, Moriyama Y and Asano G: Overexpression and localization of heat shock proteins mRNA in pancreatic carcinoma. J Nippon Med Sch 67: 177-185, 2000.

36. Kennedy NJ, Cellurale C and Davis RJ: A radical role for p38 MAPK in tumor initiation. Cancer Cell 11: 101-103, 2007.

37. Khan EM, Heidinger JM, Levy M, Lisanti MP, Ravid T and Goldkorn T: Epidermal growth factor receptor exposed to oxidative stress undergoes Src- and caveolin-1-dependent perinuclear trafficking. J Biol Chem 281: 14486-14493, 2006.

38. Oksvold MP, Huitfeldt HS, Ostvold AC and Skarpen E: UV induces tyrosine kinase-independent internalisation and endosome arrest of the EGF receptor. J Cell Sci 115: 793-803, 2002.

39. Feng FY, Varambally S, Tomlins SA, et al: Role of epidermal growth factor receptor degradation in gemcitabine-mediated cytotoxicity. Oncogene 26: 3431-3439, 2007.

40. Winograd-Katz SE and Levitzki A: Cisplatin induces PKB/Akt activation and p38(MAPK) phosphorylation of the EGF receptor. Oncogene 25: 7381-7390, 2006.

41. Xu W, Mimnaugh E, Rosser MF, et al: Sensitivity of mature Erbb2 to geldanamycin is conferred by its kinase domain and is mediated by the chaperone protein Hsp90. J Biol Chem 276: 3702-3708, 2001. 